\title{
Neuropsychology of reward learning and negative symptoms in schizophrenia
}

\section{Citation}

Nestor, Paul G., Victoria Choate, Margaret Niznikiewicz, James J. Levitt, Martha E. Shenton, and Robert W. McCarley. 2014. "Neuropsychology of Reward Learning and Negative Symptoms in Schizophrenia." Schizophrenia Research 159 (2-3) (November): 506-508. doi:10.1016/ j.schres.2014.08.028.

\section{Published Version}

doi:10.1016/j.schres.2014.08.028

\section{Permanent link}

http://nrs.harvard.edu/urn-3:HUL.InstRepos:28538484

\section{Terms of Use}

This article was downloaded from Harvard University's DASH repository, and is made available under the terms and conditions applicable to Open Access Policy Articles, as set forth at http:// nrs.harvard.edu/urn-3:HUL.InstRepos:dash.current.terms-of-use\#OAP

\section{Share Your Story}

The Harvard community has made this article openly available.

Please share how this access benefits you. Submit a story.

\section{Accessibility}




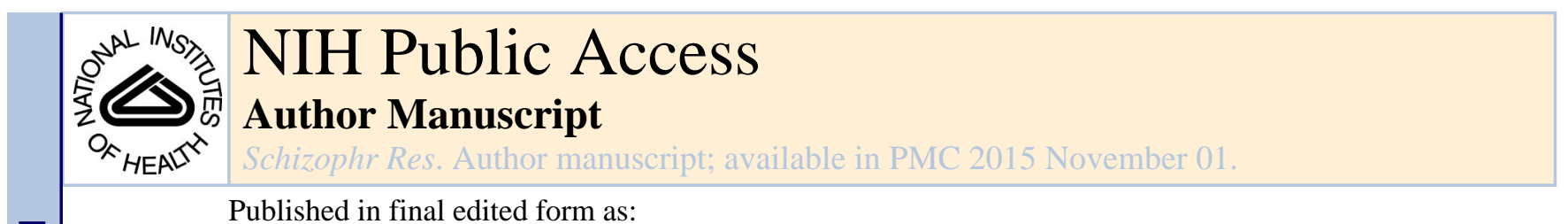

Published in final edited form as:

Schizophr Res. 2014 November ; 159(0): 506-508. doi:10.1016/j.schres.2014.08.028.

\title{
Neuropsychology of Reward Learning and Negative Symptoms in Schizophrenia
}

\author{
Paul G. Nestor, Ph.D. ${ }^{1,2}$, Victoria Choate, MA ${ }^{1,2}$, Margaret Niznikiewicz, Ph.D. ${ }^{2}$, James J. \\ Levitt, M.D. ${ }^{2,3}$, Martha E Shenton, Ph.D ${ }^{2,3}$, and Robert W. McCarley, M.D. ${ }^{2}$ \\ ${ }^{1}$ Department of Psychology, University of Massachusetts, Boston, MA \\ ${ }^{2}$ Clinical Neuroscience Division, Laboratory of Neuroscience, Boston VA Healthcare \\ SystemBrockton Division, Department of Psychiatry, Harvard Medical School, Brockton, MA \\ ${ }^{3}$ Psychiatry Neuroimaging Laboratory, Department of Psychiatry, Brigham and Women's Hospital, \\ Harvard Medical School, Boston, MA
}

\begin{abstract}
We used the Iowa Gambling Test (IGT) to examine the relationship of reward learning to both neuropsychological functioning and symptom formation in 65 individuals with schizophrenia. Results indicated that compared to controls, participants with schizophrenia showed significantly reduced reward learning, which in turn correlated with reduced intelligence, memory and executive function, and increased negative symptoms. The current findings suggested that a disease-related disturbance in reward learning may underlie both cognitive and motivation deficits, as expressed by neuropsychological impairment and negative symptoms in schizophrenia.
\end{abstract}

\section{Introduction}

Disruptions in learning and motivation have long been viewed as central to both neuropsychology and symptom formation of schizophrenia. Indeed, neuropsychological studies frequently have revealed widespread deficits with most pronounced impairments in declarative memory as well as executive attentional function, each of which may reflect dissociable disturbances with distinct pathophysiology (Cannon et al., 2000; Nestor et al., 2004; Nestor et al., 2008). Likewise, both negative and positive symptoms are defining features of schizophrenia, with the former characterized by diminished levels of motivation, emotional expressivity, social engagement, and social attention, and the latter by delusions, hallucinations, and thought disturbance (Andreasen 1992). However, whether positive and negative symptoms reflect a common or different underlying pathophysiology remains an open question (Crow, 1980).

(C) 2014 Elsevier B.V. All rights reserved.

Address reprint requests to Paul G. Nestor, Department of Psychology, University of Massachusetts, Boston, MA 02125-3393; phone: 617-287-6387; paul.nestor@umb.edu.

Publisher's Disclaimer: This is a PDF file of an unedited manuscript that has been accepted for publication. As a service to our customers we are providing this early version of the manuscript. The manuscript will undergo copyediting, typesetting, and review of the resulting proof before it is published in its final citable form. Please note that during the production process errors may be discovered which could affect the content, and all legal disclaimers that apply to the journal pertain. 
Here we used the Iowa Gambling Test (IGT), a standardized measure of motivated decision making to probe the dynamics of reward learning (e.g., Bechara et al., 1994) in schizophrenia (e.g., Sevy et al., 2007). Findings from fMRI studies (e.g., Preuschoff et al., 2008) have suggested that this learning relies heavily on prediction error processes; expectations are generated from extracting the ambiguous probabilities of the four card decks, which comprised the IGT, and these can be tested against the actual result of each selection. Outcomes that violate expectancies facilitate learning by capturing attention (e.g., Mackintosh, 1975). Hence, the veridical capacity to detect a mismatch between expectations and actual outcome, that is to recognize a prediction error and to adjust subsequent choices, accordingly, may very well represent an important information-processing mechanism underlying performance on the IGT. We predicted that schizophrenia will be associated with impaired reward learning, as assessed by the IGT, which will be associated with diseaserelated reductions in intelligence, executive functioning, and declarative memory, as assessed by neuropsychological tests, and in motivation, as assessed by negative symptom ratings.

\section{Method}

Research participants were between the ages of 17 and 55 years, right-handed, native speakers of English, without histories of ECT, neurological illness, and without alcohol or drug abuse in the past 5 years. All research participants gave informed consent prior to their participation in the study. Diagnoses for patient group were ascertained by the Structured Clinical Interview for DSM-IV Axis I Disorders-Patient Edition (SCID-P), along with chart review. All patients were part of an ongoing comprehensive, longitudinal study of schizophrenia, and all were receiving neuroleptic medication; the mean chlorpromazine (CPZ) equivalent daily dose was $469.03 \mathrm{mg}(\mathrm{SD}=377.48)$. The mean duration of illness was 16.17 years $(\mathrm{SD}=11.88)$. All patients were rated on The Scale for the Assessment of Negative Symptoms (SANS) and the Scale for the Assessment of Positive Symptoms (SAPS) (Andreasen, 1983, 1984). Control participants, recruited from newspaper advertisement, underwent the SCID-NP, and were equated to patients on the basis of age, sex, handedness, and parental SES (See Table 1). Sixty-five patients and 65 healthy controls completed the IGT. These participants also completed the Wisconsin Card Sorting Test (WCST) (48 patients, 52 healthy controls), Wechsler Adult Intelligence Scale-Third Edition (WAIS-III) IQ (51 patients, 46 healthy controls), Wechsler Memory Scale-Third Edition (WMS-III) (56 patients, 45 healthy controls).

\section{Results}

Table 1 presents test scores on measures of intelligence, memory and executive function for the two groups. These scores were submitted to an analysis of covariance (ANCOVA), controlling for group differences in education. For the WAIS-III, in relation to the control group, the patient group scored significantly lower on WAIS-III full-scale, verbal and performance IQ measures, F $(1,72)=6.43 . \mathrm{p}=.013$, Partial Eta Squared $=.082$. Likewise for the WMS-III, in relationship to the control group, the patient group had significantly reduced scores on both immediate and delayed recall tests $\mathrm{F}(1,76)=10.69, \mathrm{p}=.002$, Partial Eta Square $=.123$. 
For the WCST in relation to the control group, the patient group completed significantly fewer categories and made significantly more both non-perseverative and perseverative errors, $\mathrm{F}(1,97)=10.21, \mathrm{p}=.002$, Partial Eta Squared $=.095$. In addition, group interacted significantly with WCS test measure (i.e., categories completed, non-perseverative errors, perseverative errors), $\mathrm{F}(2,194)=6.62, \mathrm{p}=0.002$, Partial Eta $=.064$. As shown, in Table 1, whereas the control group showed similar rates of non-perseverative $(M=12.15, S D=9.73)$ and perseverative errors $(M=12.33$, S.D. $=10.61)$, the patient group showed a relatively higher rate of perseverative $(M=23.96, S D=20.15)$ than non-perseverative $(M=18.60, S D$ $=11.61$ ) errors.

For the IGT, ANCOVA revealed that the patient group had overall lower net earnings in dollars $(\mathrm{M}=\$-1.94$, S.D. $=25.24)$ than did the control $(\mathrm{M}=\$ 14.25, \mathrm{SD}=27.44)$ group, $\mathrm{F}$ $(1,127)=3.90, \mathrm{p}=0.05$, Partial Eta $=.030$. Follow-up comparisons indicated both groups did not differ in their IGT net-gain score for the first 20 trials of blocks. However as shown in Figure 1, in relation to the control group, the patient group recorded significantly reduced net-gain scores for block 2, F $(1,129)=7.91, \mathrm{p}=0.006$, Partial Eta Squared $=.058$, block 3, $\mathrm{F}(1,129)=4.65 \mathrm{p}=0.033$, Partial Eta Squared $=.035$, block $4, \mathrm{~F}(1,129)=9.486, \mathrm{p}=$ 0.003 , Partial Eta Squared $=.068$, and block 5, F $(1,129)=4.86, \mathrm{p}=0.029$, Partial Eta Squared $=.036$ (see Table 1). Total IGT net gain score correlated with full-scale IQ for patient, $\mathrm{r}(49)=.383, \mathrm{p}=.006$ and control, $\mathrm{r}(43)=.324, \mathrm{p}=.030$ ) groups. In addition, for the patient group only, total IGT net gain score correlated with immediate memory, $\mathrm{r}(54)=$. $410, p=.002$ and total number of correct for the WCST, $r(59)=.272, p=.034$.

Last, Table 2 presents mean SANS and SAPS ratings for the patient group. For the patient group, higher negative symptom ratings on the SANS correlated with lower total net IGT gain, $r(47)=-0.281, p=0.05$, fewer card selections from the two advantageous decks, $r$ $(47)=-0.28, p=0.05$ and increased card selections from the two disadvantageous decks, $r$ $(47)=0.28, p=0.05$. SANS did not correlate with any of the other neuropsychological measures. Neither duration of illness nor CPZ equivalent daily dose correlated with symptoms ratings or with any of the neuropsychological summary scores.

\section{Discussion}

In relation to controls, research participants with schizophrenia showed significantly reduced reward learning as measured by the IGT. This overall reduction occurred despite both groups showing similar performance over the first block of 20 IGT trials. Whereas for both groups IGT correlated with IQ, only for the schizophrenia group did reduced reward learning on the IGT correlate with memory and executive function and also with negative symptoms. In addition, the neuropsychological data pointed to effect sizes of considerable magnitude ranging from medium for disease-related deficits in intelligence, executive function, and reward learning to large for the impairment in declarative memory of the patient group (Cohen, 1988). These deficits are consistent with prior research, and underscore the powerful, deleterious effect of schizophrenia on neuropsychological development and function (Heinrichs, 2005; Woodberry et al., 2008). 
Taken together, these results suggest that impaired motivational processes, as assessed by the IGT, may represent a common denominator uniting neuropsychological and clinical expressions of schizophrenia. Prior research (Corlett, et al. 2009; Fletcher \& Frith, 2009; Gradin et al., 2011) has proposed disease-related abnormalities in dopamine-mediated neural encoding of prediction errors as underlying faulty learning and symptom formation in schizophrenia. One important question raised by the current results centers on whether schizophrenia targets the prediction error system, and by doing so compromises this allpurpose mechanism for learning, leading to both cognitive and motivation deficits, which were expressed by reduced neuropsychological performance and negative symptoms, respectively, in this current study. However, a more general deficit in working memory may also detract from IGT performance as well as contribute to negative symptoms.

The current study is limited by the fact that the IGT does not allow performance to be decomposed into specific information processes and mechanisms (Busemeyer \& Stout, 2002). Another important limitation of the current study is the very modest, uncorrected for multiple comparisons, correlation of symptoms and IGT, striking in contrast to the highly statistically significant correlations of IGT with both intelligence and memory. Finally, the current study focused only on medicated patients with chronic schizophrenia and relied exclusively on behavioral measures of neuropsychological functioning and symptom recordings.

\section{Acknowledgments}

This work was supported by the National Institute of Health (R01 MH 40799 and P50 080272 to RWM, RO1 MH 63360 to MN, RO1 MH50747, K05 MH 070047, and P50 080272 to MES), the Department of Veterans Affairs Merit Awards (RWM, JJL, MES), and the Department of Veterans Affairs Schizophrenia Center (RWM, MES).

\section{References}

Andreasen NC, Flaum M, Arndt S. The Comprehensive Assessment of Symptoms and History (CASH): an instrument for assessing diagnosis and psychopathology. Archives of General Psychiatry. 1992; 49(8):615-623. [PubMed: 1637251]

Bechara A, Damasio AR, Damasio H, Anderson SW. Insensitivity to future consequences following damage to human pre-frontal cortex. Cognition. 1994; 50(1-3):7-15. [PubMed: 8039375]

Busemeyer JR, Stout JC. A contribution of cognitive decision models to clinical assessment: decomposing performance on the Bechara gambling task. Psychological Assessment. 2002; 14(3): 253-262. [PubMed: 12214432]

Cannon TD, Huttunen MO, Lonnqvist J, Tuulio-Henriksson A, Pirkloa T, Glahn D, Finkelstein J, Hietanen M, Kaprio J, Koskenvuo M. The inheritance of neuropsychological dysfunction in twins discordant for schizophrenia. American Journal of Human Genetics. 2000; 67:369-382. [PubMed: 10880296]

Cohen, J. Statistical power analysis for the behavioral sciences. second. Erlbaum; New Jersey: 1988.

Corlett PR, Frith CD, Fletcher CD. From drugs to deprivation: a Bayesian framework for understanding models of psychosis. Psychopharmacology (Berl). 2009; 206(4):515-530. [PubMed: 19475401]

Crow TJ. Molecular pathology of schizophrenia: more than one disease process? British Medical Journal. 1980; 280:66-68. [PubMed: 6101544]

Fletcher PC, Frith CD. Perceiving is believing: a Bayesian approach to explaining the positive symptoms of schizophrenia. Nature Review Neuroscience. 2009; 10(1):48-58. 
Gradin VB, Kumar P, Walter G, Ahearn T, Stickle C, Milders M, Reid I, Hall J, Steele D. Expected value and prediction error abnormalities in depression and schizophrenia. Brain. 2011; 134(6): 1751-1764. [PubMed: 21482548]

Heinrichs R. The primacy of cognition in schizophrenia. American Psychologist. 2005; 60(3):229242. [PubMed: 15796677]

Mackintosh NJ. A theory of attention: variations in associability of stimuli with reinforcement. Psychological Review. 1975; 82(4):276-298.

Nestor PG, Kubicki M, Gurrera RJ, Niznikiewicz M, Frumin M, McCarley RW, Shenton ME. Neuropsychological correlates of diffusion tensor imaging in schizophrenia. Neuropsychology. 2004; 18(4):629-637. [PubMed: 15506830]

Nestor PG, Kubicki M, Niznikiewicz M, Gurrera RJ, McCarley RW, Shenton ME. Neuropsychological disturbance in schizophrenia: A diffusion tensor imaging study. Neuropsychology. 2008; 22(2):246-254. [PubMed: 18331167]

Preuschoff K, Quartz SR, Bossaerts P. Human insula activation reflects risk prediction error as well as risk. Journal of Neuroscience. 2008; 28(11):2745-2752. [PubMed: 18337404]

Sevy S, Burdick KE, Visweswaraiah H, Abdelmessih S, Lukim M, Yechiam E, Bechara A. Iowa Gambling Task in schizophrenia. A review and new data in patients with schizophrenia and cooccurring cannabis use disorder. Schizophrenia Research. 2007; 92(1-3):74-84. [PubMed: 17379482]

Woodberry KA, Giuliano AJ, Seidman LJ. Premorbid IQ in schizophrenia: A meta-analytic review. The American Journal of Psychiatry. 2008; 165(5):579-587. [PubMed: 18413704] 


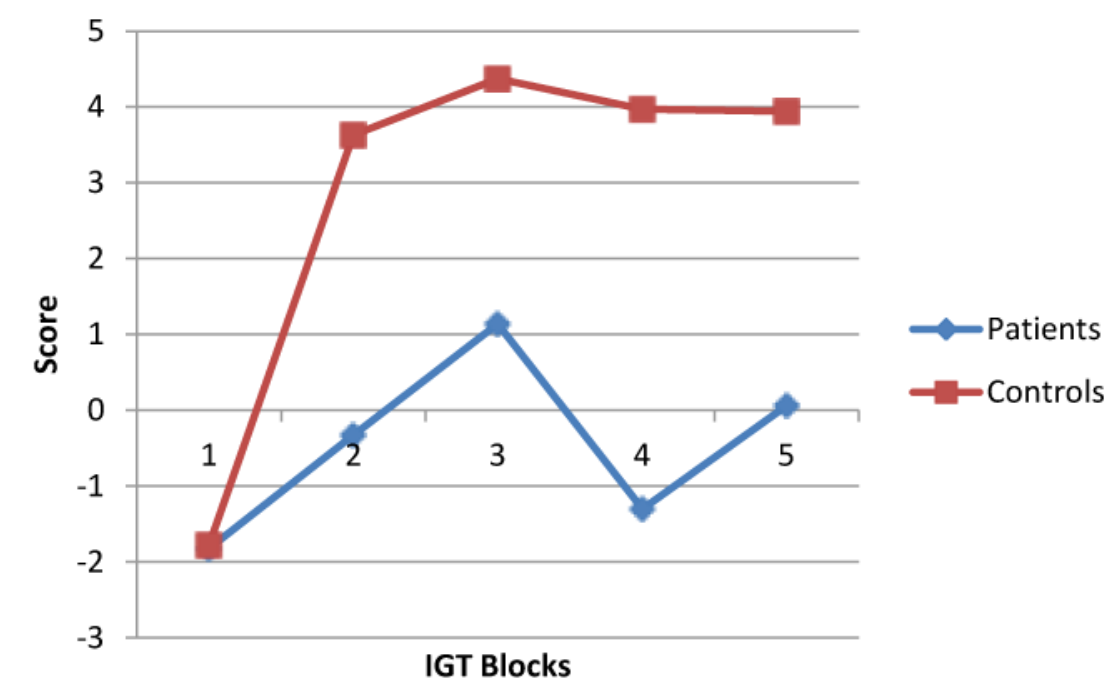

Figure 1.

IGT performance for patient and control groups 


\section{Table 1}

Neuropsychological scores for participants with schizophrenia and healthy controls.

\begin{tabular}{lcc}
\hline Demographic Information & Schizophrenia & Controls \\
Age & $42.19 \pm 10.00$ & $41.59 \pm 8.49$ \\
Education & $13.32 \pm 1.93$ & $14.90 \pm 1.96$ \\
SES & $3.38 \pm 1.23$ & $2.22 \pm 0.92$ \\
Parental SES & $2.78 \pm 1.18$ & $2.54 \pm 1.06$ \\
IGT & & \\
Block 1 & $-1.88 \pm 9.77$ & $-1.78 \pm 10.10$ \\
Block 2 & $-0.33 \pm 8.31$ & $3.63 \pm 7.89$ \\
Block 3 & $1.21 \pm 8.16$ & $4.37 \pm 9.02$ \\
Block 4 & $-1.29 \pm 9.74$ & $3.97 \pm 9.94$ \\
Block 5 & $0.03 \pm 10.00$ & $3.94 \pm 10.20$ \\
Total Net & $-1.94 \pm 25.24$ & $14.25 \pm 27.44$ \\
WAIS-III IQ & & \\
Full Scale & $93.51 \pm 12.96$ & $107.51 \pm 15.40$ \\
Verbal & $96.06 \pm 13.78$ & $107.22 \pm 14.18$ \\
Performance & $91.08 \pm 12.82$ & $106.18 \pm 16.80$ \\
WMS-III Memory Quotient & & \\
Immediate Memory & $85.25 \pm 17.37$ & $101.87 \pm 15.21$ \\
Delayed Memory & $89.35 \pm 14.64$ & $103.02 \pm 13.16$ \\
WMS-III Index & & \\
Auditory Immediate & $89.62 \pm 15.21$ & $103.33 \pm 14.76$ \\
Visual Immediate & $85.52 \pm 17.17$ & $98.82 \pm 15.07$ \\
Auditory Delayed & $95.02 \pm 15.77$ & $106.36 \pm 13.56$ \\
Visual Delayed & $87.33 \pm 16.61$ & $101.14 \pm 14.21$ \\
WCST & & \\
Categories Completed & $3.77 \pm 2.31$ & $5.22 \pm 1.61$ \\
Non perseverative errors & $18.60 \pm 11.61$ & $12.15 \pm 9.73$ \\
Perseverative errors & $23.96 \pm 20.15$ & $12.33 \pm 10.61$ \\
\hline
\end{tabular}

Note. Values are means plus or minus standard deviations. SES = socioeconomic status; IGT= Iowa Gambling Test (IGT); WAIS-III = Wechsler Adult Intelligence Scale---Third Edition; WMS-III Wechsler Memory Scale---Third Edition; WCST=Wisconsin Card Sorting Test. 


\section{Table 2}

Positive and negative symptom ratings for patients with IGT

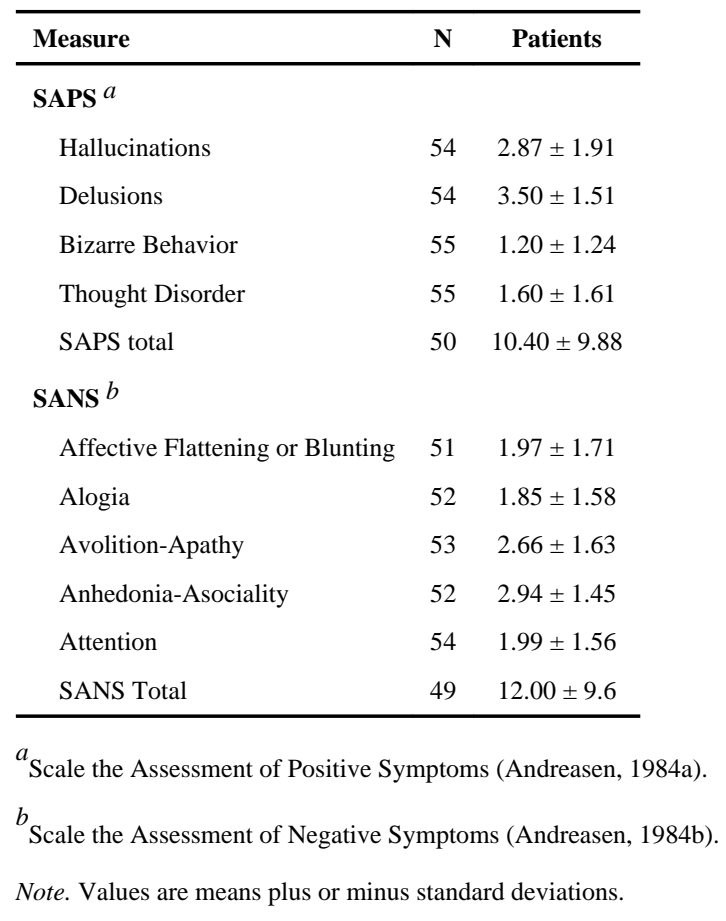

Schizophr Res. Author manuscript; available in PMC 2015 November 01. 